\title{
Natur, kärlek och den manliga maktens gränser
}

\section{Lena Gunnarsson}

SAMMANDRAG: Det har länge varit något av ett tabu för feministiska teoretiker att hänvisa till naturen i begreppsliggörandet av könsrelationer. I sin artikel kritiserar Lena Gunnarsson denna naturfobi och argumenterar för att vi behöver förankra samhällsteorier i ett explicit begrepp om de naturgivna nödvändigheter som varje samhällelig struktur beror av och i slutänden måste anpassa sig till. Vi behöver förhålla oss till en "naturlig ontologisk ordning" inte bara för att kunna förklara hur maktstrukturer får fäste i människor, utan också för att kunna precisera hur naturgivna nödvändigheter sätter absoluta gränser för förtrycksstrukturernas möjliga former, och därmed i sista hand grundlägger ett intresse av att upphäva dessa förtryckande strukturer. Naturen är inblandad i den mänskliga sociala sfären bland annat genom de grundläggande mänskliga behov som varje samhälle måste möta för att reproducera sig självt. Ett sådant mänskligt behov som ofta förbisetts teoretiskt om än antagits implicit är behovet av kärlek. Med utgångspunkt i Anna G. Jónasdóttirs teori om "kärlekskraft" analyserar Gunnarsson de motsättningar som är inneboende i den makt som män tillägnar sig genom att exploatera kvinnors kärlek, och argumenterar för att dessa motsättningar kan förstås endast med hänvisning till naturgivna nödvändigheter.

NYCKELORD: genus; kön; feminism; Anna G. Jónasdóttir; kärlek; kärlekskraft; sexualitet; sexköp; kritisk realism; natur.

PUBLICERINGSHISTORIK: Översättning av artikeln "Nature, love and the limits of male power" från Journal of Critical Realism, volym I4, nr 32015 (DOI: https://doi.org/IO.II79/ I476743015Z.0000000007I).

LENA GUNNARSSON är forskare i genusvetenskap vid Örebro universitet.

E-POSTADRESS: lena.gunnarsson@oru.se

FÖRSLAG PÅ KÄLLANGIVELSE:

Gunnarsson, Lena (20I7) "Natur, kärlek och den manliga maktens gränser”, i Arkiv. Tidskrift för sambällsanalys, nr 8, s. 77-86.

DOI: https://doi.org/I0.13068/2000-6217.8.3

(C) original: Taylor \& Francis Ltd 2015, http://www.tandfonline.com

(C) svensk version: Lena Gunnarsson/Arkiv förlag \& tidskrift 2017

(publicerad 8 juni 20I7)

Artikeln distribueras enligt en upphovsrättslicens från Creative Commons:

Erkännande-Ickekommersiell-IngaBearbetningar 3.0 Unported, som medger fri ickekommersiell användning och spridning i oförändrat skick så länge källan anges. 
Arkiv. Tidskrift för samhällsanalys är en sakkunniggranskad vetenskaplig tidskrift för samhällsvetenskap och historia. Samtliga artiklar publiceras fritt tillgängliga på:

$$
\text { www.tidskriftenarkiv.se }
$$

Beständig länk, DOI: https://doi.org/IO.I3068/2000-62I7

Den här artikeln finns tillgänglig i följande format:

PDF \& HTML: via beständig länk, DOI: https://doi.org/IO.I3068/2000-62I7.8.3

EPUB: ingår i e-boksutgåva av numret, ISBN: 978 9I 79242909

TRYCK: ingår i bokutgåva av numret, ISBN: 978 9I 7924 29I 6

Grafisk utformning och sidnumrering är identisk i pdf och tryck.

Samtliga artiklar i nr 8 (20I7) nås via beständig länk, DOI: https://doi.org/I0.13068/2000-6217.8

Arkiv. Tidskrift för samhällsanalys

ISSN: 2000-62I7 (för elektronisk resurs)

ISSN: 2000-6225 (för tryckta nummer)

ges ut av

Stiftelsen Arkiv för främjande och spridning av samhällsvetenskaplig och historisk forskning

genom

Arkiv förlag \& tidskrift

Box 1559

SE-22I OI Lund

BESÖK: L Gråbrödersg 3 c, ipg

TEL: 046-I3 3920

ARKIV FÖRLAG: arkiv@arkiv.nu·www.arkiv.nu

TIDSKRIFTEN ARKIV: red@tidskriftenarkiv.se.www.tidskriftenarkiv.se

ANSVARIg UTGIVARE \& CHEFREDAKTÖR: Sven Hort

Administrativ Redaktör: David Lindberg

Redaktörer: Paavo Bergman, Per Dannefjord, Lisa Kings,

Zhanna Kravchenko, Anna-Maria Sarstrand Marekovic 


\section{Natur, kärlek och den manliga maktens gränser}

\section{LENA GUNNARSSON}

Alla försök att analysera och förklara en socialt konstruerad förtrycksstruktur måste bygga på något begrepp om en "naturlig ontologisk ordning" (Collier 2002, s. I66). Vi behöver kunna hänvisa till naturgivna villkor inte bara för att förklara hur maktstrukturer kan koppla grepp om människor, utan också för att precisera hur den naturliga ontologiska ordningen sätter absoluta gränser för förtrycksstrukturernas möjliga former, något som i sista hand grundlägger ett intresse av att upphäva dem.

Frågan om naturens samhällsteoretiska relevans är särskilt angelägen för feministisk teori, med tanke på den starka naturfobi som behärskar fältet i dag (Gunnarsson 20I3, 20I4). Det feministiska tabut mot naturen beror delvis på det starka inflytande som poststrukturalismen utövat på feministisk teori, men på ett mer allmänt plan också på det faktum att patriarkala könsrelationer i regel legitimeras med hänvisning till en naturlig ontologisk ordning. Det är alltså knappast förvånande att feminister är en aning misstänksamma mot naturen. Den naturfientliga håll-

Artikeln är en omarbetad version av ett anförande som hölls vid International Association for Critical Realisms konferens den 20 juli 2014 vid Institute of Education i London, med anledning av författarens mottagande av Cheryl Frank Memorial Prize för sin bok The contradictions of love (2014). Den publicerades ursprungligen som "Nature, love and the limits of male power", i Journal of Critical Realism, volym I4, nr 32015 (DOI: https://doi.org/I0.1179/1476743015Z.0000000007I) och publiceras här med tillstånd från Taylor \& Francis Ltd. 
ningen är emellertid problematisk, eftersom uppfattningen att naturen inte har någon som helst betydelse för de sociala relationerna reproducerar det deterministiska naturbegrepp som den patriarkala ideologin vilar på. Frågan som förblir obesvarad när vi inte grundar våra samhällsteorier i naturen är varifrån de maktstrukturer som vi analyserar hämtar sin styrka, om det nu inte finns några grundläggande villkor som strukturerna kan haka i, som gör människor mottagliga för dem. Därutöver har vi den normativa frågan om hur vi kan påstå att en struktur är förtryckande i frånvaro av givna behov som inte kan bortkonstrueras och som inte tillgodoses inom strukturen $\mathrm{i}$ fråga.

Den feministiska teoretikern och statsvetaren Anna G. Jónasdóttir utgör ett undantag från denna regel om feministisk naturfobi (2002, 2003 [1994], 2009, 201I). Hennes patriarkatsteori grundar sig på uppfattningen att människor av naturen är utrustade med förmåga till såväl som behov av kärlek. Hennes kärleksbegrepp inskränker sig inte till en föreställning om romantisk kärlek eller den känsla man upplever när man säger att man älskar någon. Hon arbetar med ett mycket bredare begrepp, där kärlek uppfattas som den kraft med hjälp av vilken vi kan bekräfta varandra som personer, som värdiga mänskliga existenser i stånd till verkningsfullt handlande i den sociala världen. Vi kan reproducera oss som biologiska varelser utan kärlek, men inte som det vi menar med personer. Kärlek för Jónasdóttir består i ett dialektiskt förhållande mellan omsorg och erotisk extas och genomsyrar samhällsstrukturen som helhet, även om den är koncentrerad till de intima band som blir formella genom äktenskapsinstitutionen.

Jónasdóttirs feministiska tes är att den makt som män utövar i egenskap av män i dagens västerländska patriarkat, där det råder formell jämlikhet mellan könen och där kvinnor är mer eller mindre ekonomiskt oberoende av enskilda män, i sista hand bygger på en specifik exploateringsmodell i fråga om kärlekens organisering. Män exploaterar kvinnors kärlek, menar hon. Jónasdóttir griper tillbaka på en marxistisk och historiematerialistisk förklaringsmodell, brett uppfattad, och drar en parallell till kapitalismen: om exploateringen av arbetskraft ger upphov till kapital och fattigdom, ger mäns exploatering av kärlek upphov till manlig auktoritet och kvinnlig ovärdighet. För de flesta kvinnor blir 
följden av detta en "ständig kamp på 'fattigdomens' rand när det gäller möjligheten att verka i samhället med självsäkerhet och självklar värdighet, att utöva sina förmågor på ett ändamålsenligt och legitimt sätt" (Jónasdóttir 2003 [1994], s. 239, ändrad översättning). Den manliga auktoritetens strukturella drag ger män tillgång till en "mervärdighet" (ibid., s. 24I), som inaktualiserar eller döljer deras behov av kärlek, deras beroende av andra människor, medan den kvinnliga bristen och beroendet framhävs av exploateringsprocessen.

Vi kan tänka oss detta utifrån Roy Bhaskars distinktion mellan kraft / begränsning-relationer (power/constraint), bestående av livskrafterna och livsbegränsningarna i den naturliga ontologiska ordningen, och de förtryckande, politiska, onödiga makt/begränsning -relationerna (power / constraint ${ }_{2}$, som grundar sig på de förra utan att deterministiskt följa av dem (Bhaskar 2008 [1993]). Vi begränsas alla av vårt behov av kärlek, men i kärlekens exploateringsstruktur stegras kvinnors behov och formar sig till en alienerad typ av begränsning. Mäns behov däremot döljs av deras strukturella tillgång till kvinnors livskrafter, vilket på sätt och vis befriar dem från varats grundläggande begränsningar, fastän de i grund och botten, egentligen, är lika sårbara och beroende som kvinnor.

Här ser vi att den naturliga ontologiska ordningens begränsningar grundlägger och möjliggör exploateringsordningen. Vi kan inte förstå varför kvinnor blir kvar i relationer med män som tömmer dem på kraft om vi inte grundar vår analys på det faktum att kvinnor behöver kärlek. Om inte människor begränsades av sina behov skulle de inte behöva underkasta sig detta slags struktur. Men samtidigt sätter naturen gränser för de socialt konstruerade maktstrukturernas former och räckvidd. Detta illustreras av det faktum att mäns patriarkala oberoende och självtillräcklighet paradoxalt nog är beroende av deras strukturella tillgång till kvinnors kärlekskraft. Män har alltså egentligen inte större makt och oberoende än kvinnor, något som ger upphov till inre motsägelser i mäns makt (mer om detta strax). På samma sätt som strejken kan synliggöra kapitalisternas beroende av arbetskraft, skulle ett kvinnligt undandragande från män, en kärleksstrejk, återaktualisera mäns sårbarhet.

Kärlekens naturliga ontologiska ordning sätter gränser för den manliga makten även på ett annat sätt. Ett utmärkande och ofrånkomligt 
drag hos kärleken är att den inte kan utvinnas med tvång; den kan inte framtvingas, styras eller köpas. Vi kan tvinga någon att låtsas älska oss och göra alla de praktiska ting som vi förknippar med kärlek - smeka oss, laga mat åt oss, ha sex med oss - men vi kan inte styra över den värdering av oss som är kärnan i kärlek. Jónasdóttir framhäver detta när hon påpekar att den kärlek som män exploaterar måste ges frivilligt, även om det, i likhet med den situation där arbetaren frivilligt ingår ett anställningsavtal, rör sig om en strukturellt betingad frivillighet som bottnar i existentiell fattigdom, bristande värdighet (Jónasdóttir 2003 [1994]). Vad Jónasdóttir inte utvecklar är emellertid hur kvinnors strukturella ofrihet påverkar den kärlek som de frivilligt ger män. Hon slår fast att det rör sig om en alienerad typ av kärlek, men reder inte ut vad detta innebär.

För att kasta lite ljus över förhållandet mellan kärlek och frihet vill jag börja med att citera en passus hos den marxistiske forskaren Chris Arthur. Han diskuterar här det faktum att kapitalets kontroll av arbetarna utgör ett tveeggat svärd:

[P] roblemet för kapitalet [är] att det behöver arbetarnas aktiva kraft. Det handlar egentligen inte om att reducera arbetaren till ett rent medel i produktionen, liksom en maskin eller ett djur vars vilja måste brytas ner. [...] Produktionens tidigare 'subjekt' behandlas som formbara objekt, men det handlar fortfarande om att manipulera deras aktivitet, inte om att beröva dem på all subjektivitet. [...] Därav följer att även om Marx har rätt i att arbetets produktivkraft i allt väsentligt absorberas i kapitalets produktivkraft, måste man ha i minnet att kapitalet fortfarande är beroende av den. Dessutom kvarstår arbetarens undertryckta subjektivitet som ett hot mot kapitalets syften i detta avseende (Arthur 2008 [200I], s. I82-183, ändrad översättning, kursivering borttagen).

Arthur menar alltså, för att uttrycka det med mina ord, att den naturliga ontologiska ordningen sätter absoluta gränser för kapitalismen. De livskrafter som exploateras har sin egen logik, oberoende av kapitalismens logik. Kapitalets makt kan därför aldrig utsträckas till hela tillvaron. Arbetskraftens egen inneboende logik, som grundar sig i hur vi människor är skapade av naturen, "sätter gränser för de möjliga sätten att realisera, bruka och forma den" (Gunnarsson 20I4, s. I34).

Vi bör dock lägga märke till att kärlek förutsätter frihet i högre grad än arbete. Det är fullt möjligt att tvinga någon att arbeta för en och kom- 
pensera den effektivitetsförlust som beror på undertryckt subjektivitet med den typ av effektivitet som kan komma till stånd genom tvång. I fråga om kärlek är detta inte möjligt. Och detta har konsekvenser för den manliga maktens beskaffenhet i kärleksordningen. I sista hand innebär det att den manliga maktens verklighet är illusorisk. Den makt och styrka som härrör från exploateringen av kärlek är bara "halvverkliga" (demi-real), en kausalt verkande illusion (Bhaskar 2002a). Den manliga makten är bara halvverklig därför att dess verklighet bygger på illusioner, på att konstitutiva delar av den undertrycks. Detta i motsats till det som är verkligt i en naturligt grundad eller "verkligt verklig" mening, för att använda Arthurs uttryck (2009, s. I78), som inte bygger på ett förnekande av verkligheten.

Vad som måste undertryckas för att den manliga auktoriteten ska framträda är det faktum att mäns värdighet och styrka inte bottnar i deras egna förmågor. Den manliga makten kan bli verksam, kan bli verklig, först när dess grund i kvinnliga krafter förnekas; i annat fall smulas den sönder. Den manliga maktens auktoritet bygger likaledes på förnekandet av det faktum att den kärlek och aktning som kommer män till del inte bara avspeglar deras personliga egenskaper, utan är delvis strukturellt betingade. De patriarkala strukturerna ger män en värdighet som vinner dem oförtjänt kärlek och aktning, samtidigt som de ger upphov till ovärdiga kvinnor vilkas trängande behov av någon form av kärlek gör dem alltför ivriga att ge sig in i relationer som inte är ömsesidiga. Denna verklighet måste undertryckas om den kärlek som kvinnor ger män ska kunna göra sin rätta verkan, det vill säga om män ska kunna uppleva att den beror på deras älskansvärdhet. Det manliga jaget i dess patriarkala form kan alltså utöva betydande makt, men dess oförmåga att möta verkligheten gör det i grunden bräckligt.

Det patriarkala mansjagets bräcklighet kan också förstås utifrån dess inre motsägelser och jagets stratifierade struktur. Det manliga jaget i dess patriarkala form är ett egojag som upprättas i motsättning till andra jag, på så sätt att det får sin styrka av att parasitera på andras styrka. Det står också i motsatsförhållande till sitt eget mer grundläggande, "verkligt verkliga" jag - eller sitt "transcendentalt verkliga jag", för att tala med Bhaskar (2002b, s. 9I) - som inte står i motsats till andra jag utan 
är dialektiskt inbegripet i dem. Det är ett naturgivet villkor att vi inte är skilda från varandra, att vi inte står emot varandra. Egojaget, vars sårbarhet döljs på ett sätt som avskärmar det från den helhet varav det egentligen är en del, får alltså sin makt på bekostnad av detta mer grundläggande eller naturliga jag, vars styrka bygger på dess enhet med övriga kosmos. Det patriarkala manliga jaget uppstår genom att sårbarheten undertrycks, och även om detta kan kännas tryggt och stärkande, försvagar det till slut jaget eftersom sårbarhet är det som verkligen öppnar våra kanaler för den andres kraft, för kärlekskraften.

Med hjälp av exemplet prostitution ska jag illustrera hur dessa inre motsägelser i den manliga makten kan förstås. Man kan tycka att prostitution och kärlek är vitt skilda ting. Men jag arbetar som sagt med ett brett kärleksbegrepp, som omfattar såväl omsorg som erotisk-extatiska behov och förmågor. Ur mitt perspektiv kan sexköp uppfattas som ett sätt att hantera dessa grundläggande krafter och behov, om än på ett mycket alienerat sätt. Jag instämmer med Clelia Smyth Anderson och Yolanda Estes, som menar att sexköparen "söker sig till en prostituerad för att slippa omaket att ge sig in i en sexuell relation med ett annat subjekt. Genom sexköp får han ett kvinnoting utan att behöva befatta sig med en kvinna” (Anderson och Estes 1998, s. 154-155). Men om så många män har behov av sexuell tillfredsställelse genom ett objekt, ett ting, kan man undra varför det inte finns en lukrativ marknad för sexrobotar. Sexköparen vill strängt taget inte ha ett objekt; det är något hos det mänskliga subjektet som efterfrågas. Jag skulle vilja påstå att vad sexköparen egentligen är ute efter är en person, som just i egenskap av person kan skänka honom värde som person. Samtidigt är han inte beredd att godta de naturgivna villkoren för att befatta sig med andra personer, existerande i sin egen rätt. Dessa villkor, enligt vilka vi måste ge andra deras frihet, är förenade med den existentiella risken att den andra personen inte ger oss det som vi önskar eller behöver. Lösningen på detta dilemma blir att delvis betala den prostituerade för att låtsas tycka om och vilja ha sex med sexköparen. Det finns undantag från denna regel, men skenet av ömsesidighet förefaller vara det vanligaste sättet att hantera situationen, och prostituerade vittnar också om att många sexköpare hellre vill prata och bli ompysslade än ha sex (Joseph och Black 20I2; Sanders 2006). 
Vad som måste undertryckas för att detta ska fungera för sexköparen är det faktum att den prostituerade gör det bara för pengarnas skull.

På detta sätt ser vi att vi inte kan förneka de naturgivna villkoren för mellanmänsklig bekräftelse, enligt vilka vi inte kan kontrollera den vi vill bli existentiellt bekräftade av, såvida vi inte bygger vårt praktiska handlande på lögner. Problemet med att bygga vårt praktiska handlande på lögner är att det alltid finns en risk för att lögner avslöjas, och att den bekräftelse som vi får alltså visar sig vara bräcklig och i sista hand falsk. Annorlunda uttryckt: Den naturliga ontologiska ordningen ställer upp gränser som ytterst gör exploatering till en självundergrävande verksamhet. När vi bygger vår självbild och styrkeuppfattning på ett exploateringsförhållande uppstår det oundvikligen motsägelser som ständigt måste hanteras genom ytterligare undertryckanden, om de inte ska slita sönder oss inifrån. Även om exploateringen gynnar män inom ramen för själva exploateringsstrukturen, har alltså män djupare sett intresse av att inte låta sina jag bygga på den.

Även om detta borde göra även män förändringsbenägna, ska jag här inrikta mig på kvinnor som förändringens subjekt, eftersom kvinnors intresse av förändring är mer uppenbart och omedelbart. Jag menar att vi bör ställa frågan: Hur kan kvinnor bruka sina krafter på ett sätt som har störst förutsättningar att bidra till en förändring? Det är som sagt inte möjligt att kräva kärlek, varför det vore oklokt att ödsla kraft på det. Det tycks vara ganska vanligt hos kvinnor som ger mer än de får i sina relationer att klaga på männen och ställa krav på dem. Problemet är helt enkelt att detta inte brukar fungera, något som ofta är smärtsamt för kvinnor. Här tror jag att vi måste bli bättre på att hålla isär den moraliska frågan om vem som bär skulden, vem som borde ändra sig, och frågan om vad som faktiskt skulle leda till förändring.

I min bok The contradictions of love diskuterar jag möjligheten av en tudelad förändringsstrategi, som jag här bara kort berör (Gunnarsson 20I4). Den första delstrategin, som skulle kunna kallas "Lysistrates drag", bygger på den typ av "kärleksstrejk" där kvinnor kollektivt drar sig undan män och riktar mer av sin kärlekskraft mot varandra, så att deras alienerade beroende av män inaktualiseras. Ett sådant undandragande skulle återaktualisera mäns beroende av kvinnor och tvinga dem att älska 
kvinnor mera om de själva ska bli älskade, så att kvinnor behöver älska mindre för att att bli älskade. Lysistrates drag är dialektiskt förbundet med en annan delstrategi, som jag också skisserar. Denna kan uppfattas som en andlig form av politisk förändring, som sätter i fråga gängse skiljelinjer mellan det andliga och det politiska. Den bygger på Bhaskars princip om självreferentialitetens och självförändringens primat, som tillmötesgår det naturgivna villkoret att "ens reaktion på den situation man befinner sig i [är] det enda som man direkt kan påverka" (Bhaskar 2002a, s. 24I). Det effektivaste vi kan göra om vi vill förändra världen blir därmed att börja med våra egna reaktioner inför den. Det betyder att vi måste låta män vara som de är. Detta kan låta provocerande för somliga, men att släppa taget är inte detsamma som att underkasta sig män eller patriarkala relationer; det handlar bara om att acceptera att vi inte på något direkt sätt kan ändra på det som befinner sig utanför våra egna reaktioner och handlingar. Därmed måste vi också försona oss med den smärta som ofta är förknippad med att släppa taget. Att göra ständiga kontraproduktiva försök att ändra på en annan person är ofta ett sätt att skyla över den smärta som skulle välla fram om vi accepterade att den andre inte är på det sätt vi skulle vilja och att detta är något som vi inte råder över. Men det är först när vi har accepterat den andres verklighet och den smärta som detta kan medföra som vi kan börja ta itu med det som vi faktiskt kan påverka, nämligen oss själva och hur vi vill ha det med tanke på denna verklighet. Just som den manliga patriarkala makten inte är verklig i egentlig mening, är den kvinnliga maktlöshet som den bygger på verklig endast som kausalt verkande illusion. En mekanism som bidrar till kvinnors maktlöshet är att deras uppmärksamhet avleds inte bara från deras egna behov, utan också från den makt de faktiskt har över sig själva.

Att acceptera män som de är kan förstås leda till allt möjligt, även separation. Men om vi accepterar den andre och släpper kontrollen är det ett paradoxalt faktum att kärleken ofta kan blomstra, om än kanske inte på det sätt vi från början föreställt och önskat oss. På sätt och vis är det alltså möjligt att ändra på andra genom att släppa taget om dem. Kruxet är bara att min önskan att ändra på den andre aldrig får bli skälet till att jag släpper taget, eftersom jag då egentligen inte alls släpper taget. 
För att återgå till frågan om naturens samhällsteoretiska relevans, har jag utifrån ämnet kön, makt och kärlek velat visa hur den naturliga ontologiska ordningen både möjliggör och begränsar exploatering och hur begränsningarna gör att det i sista hand ligger i mäns intresse att upphöra att basera sina jag på exploatering av kvinnors omvårdande och erotiska krafter. Som vi såg i den sista delen måste vi också ta hänsyn till den naturliga ontologiska ordningens begränsningar för att kunna förändra samhället. Snarare än att fåfängt söka kringgå de naturgivna villkorens begränsningar, bör vi foga oss efter vad som är möjligt för att kunna dra nytta av den förändringskraft som dessa villkor också rymmer.

\section{Översättning: Henrik Gundenäs}

\section{Litteratur}

Anderson, Clelia Smyth och Yolanda Estes (1998) "The myth of the happy hooker. Kantian moral reflections on a phenomenology of prostitution", i Stanley G. French, Wanda Teays och Laura M. Purdy (red.), Violence against women. Philosophical perspectives (Ithaca: Cornell University Press).

Arthur, Christopher J. (2008 [200I]) "Värde, arbete och negativitet", i Fronesis nr 28, s. $166-189$.

Arthur, Christopher J. (2009) "Contradiction and abstraction. A reply to Finelli", i Historical Materialism volym I7, $\mathrm{nr}$ I, s. I70-I82. DOI: https://doi.org/IO.II63/156920609X399254

Bhaskar, Roy (2002a) Meta-Reality. The philosophy of meta-Reality, band I, Creativity, love and freedom (London: Sage).

Bhaskar, Roy (2002b) Reflections on meta-Reality. Transcendence, emancipation and everyday life (London: Sage).

Bhaskar, Roy (2008 [1993]) Dialectic. The pulse of freedom (London: Routledge).

Collier, Andrew (2002) "Dialectic in Marxism and critical realism", i Andrew Brown, Steve Fleetwood och John Michael Roberts (red.), Critical realism and Marxism (London: Routledge).

Gunnarsson, Lena (2013) "The naturalistic turn in feminist theory. A Marxist-realist contribution", i Feminist Theory volym I4, nr I, s. 3-19.

DoI: https://doi.org/IO.II77/I464700II2468567

Gunnarsson, Lena (20I4) The contradictions of love. Towards a feminist-realist ontology of sociosexuality (New York: Routledge).

Jónasdóttir, Anna G. (2002) "Kärlekskraft: feministiska frågor och Marx metod", i Häften för kritiska studier volym 35, nr 2-4, s. I6-32.

Jónasdóttir, Anna G. (2003 [1994]) Kärlekskraft, makt och politiska intressen. En teori om patriarkatet i nutida västerländska samhällen (Göteborg: Daidalos). 
ARKIV | NR 8

Jónasdóttir, Anna G. (2009) "Feminist questions, Marx's method and the theorization of 'love power"', i Anna G. Jónasdóttir och Kathleen B. Jones (red.), The political interests of gender revisited (Manchester: Manchester University Press).

Jónasdóttir, Anna G. (20II) "What kind of power is 'love power??", i Anna G. Jónasdóttir, Valerie Bryson och Kathleen B. Jones (red.), Sexuality, gender and power. Intersectional and transnational perspectives (London: Routledge).

Joseph, Lauren J. och Pamela Black (2012) "Who's the man? Fragile masculinities, consumer masculinities, and the profiles of sex work clients", i Men and Masculinities volym I5, nr 5, s. 486-506.

DoI: https://doi.org/IO.II77/I097I84XI245859I

Sanders, Teela (2006) "Female sex workers as health educators with men who buy sex: utilising narratives of rationalisations", i Social Science \& Medicine volym 62, nr Io, s. 2434-2444.

DOI: https://doi.org/IO.IOI6/j.socscimed.2005.10.033 


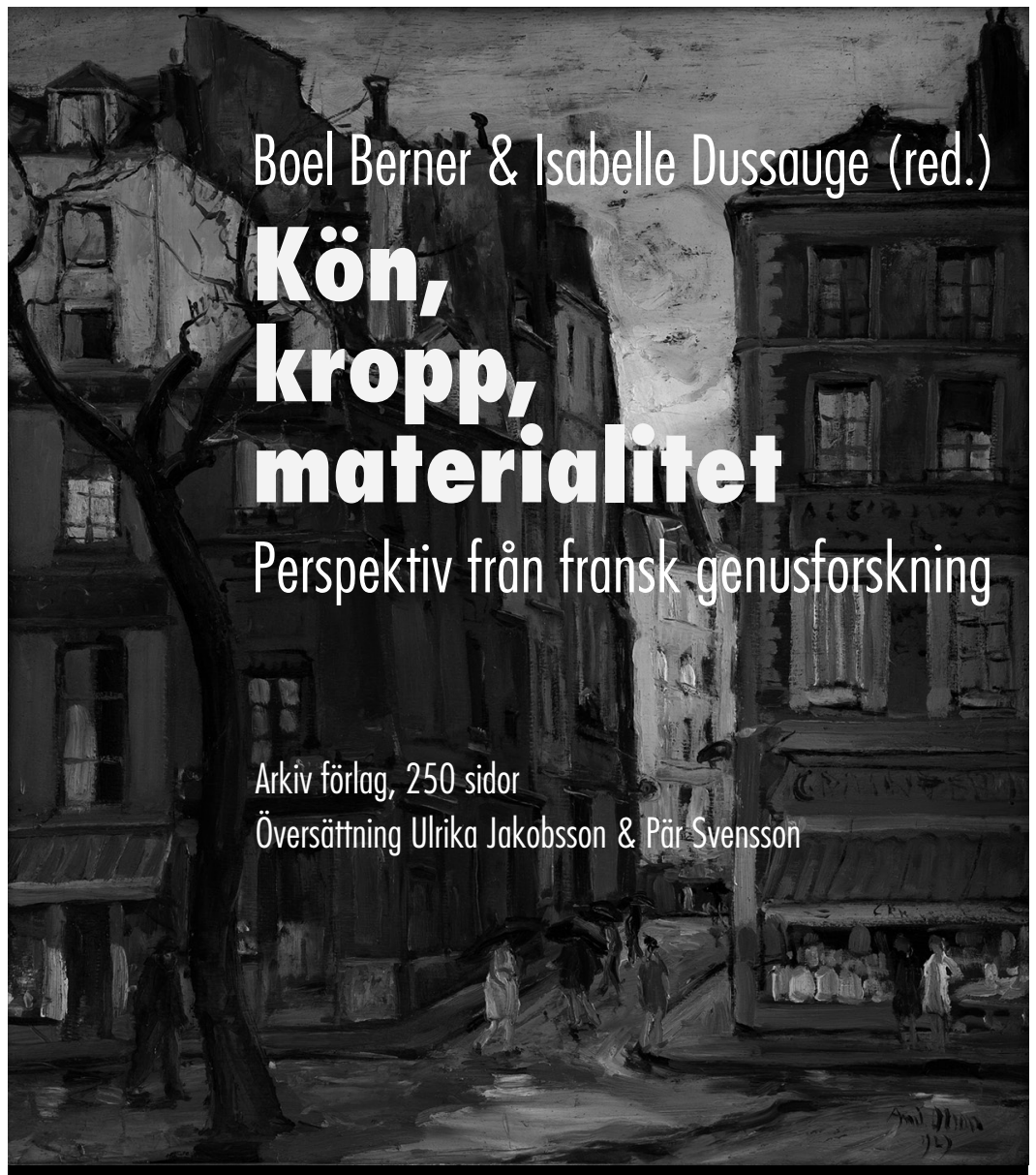

I antologin Kön, kropp, materialitet. Perspektiv från fransk genusforskning möter vi provocerande tankegångar och inspirerande resultat som nu blir tillgängliga även för en icke-franskspråkig publik. Bokens författare diskuterar växelspelet mellan könade makfförhållanden och formandet av kroppar, artefakter, medicinsk och naturvetenskaplig kunskap, i historisk tid och i dag. 
I sin kortfattade och fängslande introduktion till vetenskapsteoretiskt tänkande i samhällsvetenskapen utgår Göran Djurfeldt från den ontologiska realismen som hävdar att den materiella och mänskliga världen existerar och har bestämda egenskaper oberoende av vår uppfattning om den. Utifrån detta argumenterar han för en realistisk vetenskapsteori och är kritisk både mot positivismen i dess grova såväl som mer sofistikerade varianter och mot relativismen hos filosofer som Kuhn, Feyerabend, Rorty med flera. Boken har vuxit fram i författarens verksamhet som lärare och handledare i sociologi och framställningen är klargörande och lättläst med konkreta exempel hämtade ur författarens egen forskning.

Arkiv förlag, 110 sidor

\section{Göran Djurfeldt}

Boström och kaminen

En introduktion till realistisk vetenskapsteori 